\title{
Bypassing Health Centers in Tanzania: \\ Revealed Preferences for Observable and Unobservable
}

By

Kenneth L. Leonard, Columbia University

Gilbert R. Mliga, Ministry of Health, Tanzania

Damen H. Mariam, Addis Ababa University, Ethiopia

April 2001

Discussion Paper Series No. 0001-02 


\title{
Bypassing Health Centers in Tanzania:
}

\section{Revealed Preferences for Observable and Unobservable}

\author{
Quality* $^{*}$
}

\author{
Kenneth L. Leonard ${ }^{\dagger} \quad$ Gilbert R. Mliga ${ }^{\ddagger} \quad$ Damen Haile Mariam ${ }^{\S}$
}

April, 2001

\begin{abstract}
When patients bypass one health facility to seek health care at another, strong preferences are revealed. This paper advances the view that the patterns of bypassing observed in Iringa Rural district in Tanzania show evidence of patients' understanding of various measures of quality at the facilities that they visit and bypass. Importantly some of these measures are 'unobservable,' meaning that we do not expect patients to be able to evaluate whether or not these types of quality are present just from visiting a center. We use two data sets on various features of health facilities including consultation quality and prescription quality as evaluated by a team of clinicians. This is matched with data collected from health center registers that included the symptoms of patients and the village they traveled from. The register data is transformed into a patient-based sample and we use a multinomial/conditional logit regression on patient choice of provider to show the relationship between patient behavior and objective measure of technical quality in the health facilities. Patients seek facilities that provide high quality consultations, are staffed by more knowledgeable physicians, observe prescription practices, and are polite. They avoid facilities that use injections too liberally or over-prescribe medication.
\end{abstract}

JEL Classification: I1, O1, O2

Keywords: Health Center Bypassing, NGO, Rural Health Care, Tanzania, Technical Quality, Agency in Health Care

*We are grateful to Yoshiki Obayashi for high quality research assistance, and to participants in seminars at CSAE at Oxford, CERDI at Université d'Auvergne, Columbia University and NYU.

${ }^{\dagger}$ Corresponding author: Department of Economics, Columbia University, Mail Code 3308, $420 \mathrm{~W} 118$ th St, New York, NY 10027 (e-mail: KL206@columbia.edu), Research funded by NSF grant \#94-22768.

${ }^{\ddagger}$ Director, Human Resources Development, Ministry of Health, Tanzania.

${ }^{\S}$ Department of Community Health, Faculty of Medicine, Addis Ababa University, Ethiopia. 
When patients bypass one health facility to seek care at another, strong preferences are revealed. In rural areas, the cost of transportation is a significant portion of the cost of seeking care, and bypassing therefore suggests large differences in patients' valuations of the benefits of health at various facilities. And, indeed, there is significant variation in the quality of care available at different facilities. In Iringa rural district patients can choose between government, Lutheran and Roman Catholic health facilities. The general perception (backed up by data) is that Roman Catholic and Lutheran centers are of higher quality than government centers. Since health care is a valuable good, it should not be surprising that patients seek the care of higher quality providers, even at greater cost. However, it is not the case that patients seek these centers whenever they can, but that they sometimes seek these centers, and sometimes seek government centers. We even observe people leaving villages in which there is a high quality clinic to seek care at a low quality clinic further away.

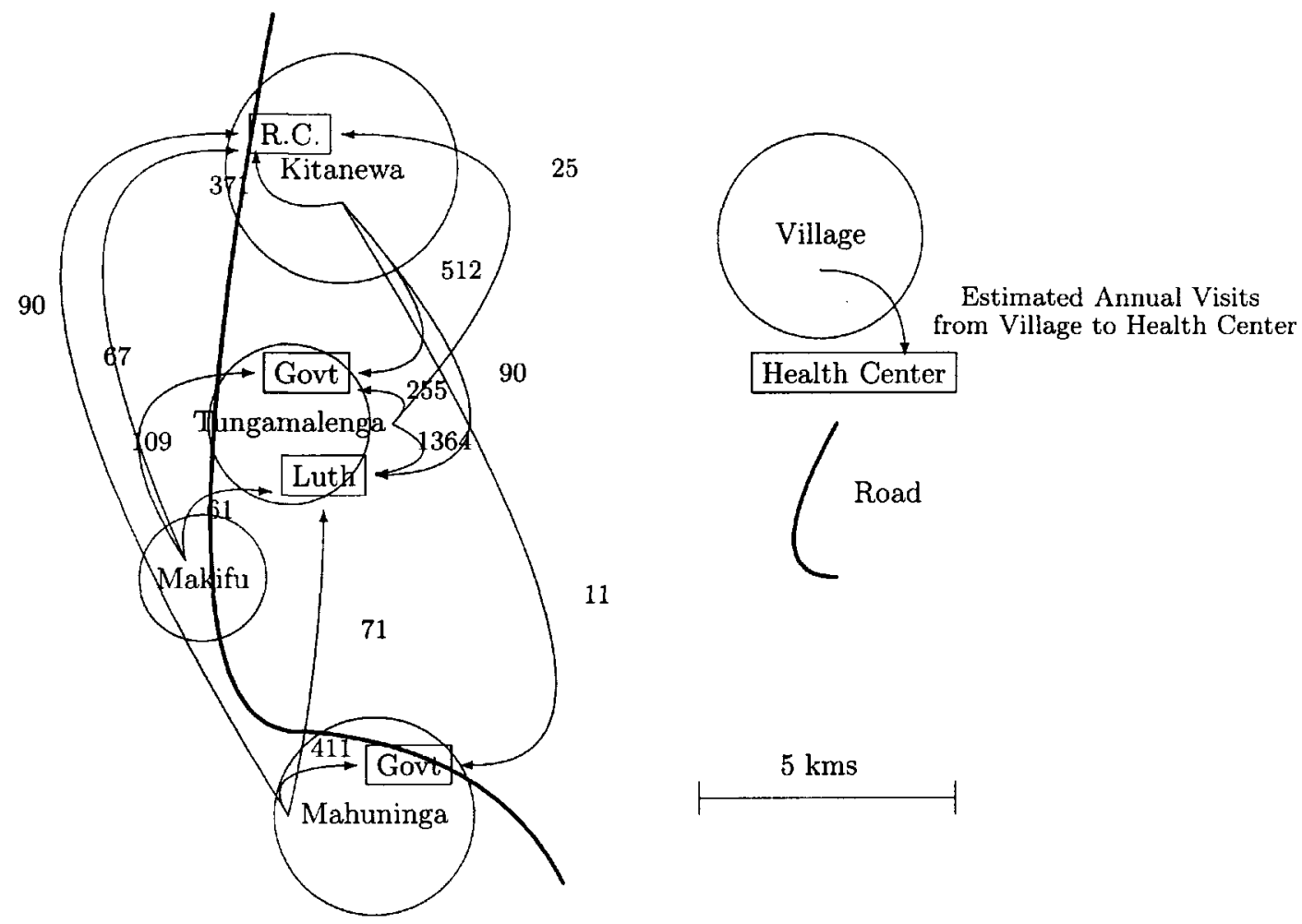

Figure 1: Estimate of annual visits to health clinics in Idodi Ward, Iringa Rural District 
Figure 1 is a stylized representation of the annual visits from a selection of villages to a selection of health facilities in Idodi ward, which is part of our sample area. There are 4 health facilities in the area; two government facilities, one Roman Catholic and one Lutheran facility. There are 4 villages $^{1}$ and the radius of each circle representing a village is proportional to the population of that village. The population of Kitanewa (the largest village) is almost 2,400 people. There are clearly too many data points in this simple graph to allow us to draw any immediate conclusions except that patients appear to be exercising significant choice. Patients are leaving Kitanewa - where they have access to a high quality clinic - to visit the government clinic in Tungamalenga, but patients are also leaving Tungamalenga to visit the Roman Catholic clinic in Kitanewa.

That distance is an important determinant of the choice of health care provider is at least as old as the analysis of Acton (1975). Almost any study of health seeking behavior in developing (and developed) countries includes some estimate of the cost of travel as an important and almost always significant variable. ${ }^{2}$ Dor et al. (1987) and Gertler and Van der Gaag (1990) even use distance as a proxy for willingness to pay in a context in which travel costs are the only measurable costs for health care. Other studies (notably Kloos, 1990; Stock, 1983) use the distance traveled to reach health facilities as a measure of barriers to access and ability to overcome them. Both studies identify an illness-specific distance gradient, or an illness-specific willingness to incur travel costs.

This paper takes the importance of distance as a starting point, and claims that we can learn from those situations in which distance alone does not determine the choice of health care provider; when patients bypass providers. Akin and Hutchinson (1999) examine this phenomenon in Sri Lanka. Their data matches a household survey to a census of health facilities. They find that the quality of the facility and the severity of the illness help to

\footnotetext{
${ }^{1}$ For expository simplicity villages that are less than $2 \mathrm{kms}$ apart are compressed to represent one village, and assigned the name of the larger village. We do this only for the Figure shown, not in the data analyzed later in the paper.

${ }^{2}$ An exception is Akin et al. (1986), who find that in the Bicol region of the Philippines, conditional on the decision to seek care within the district, distance is not a significant determinant. Although this result is provocative, it has not been reproduced in other areas of the developing world.
} 
explain bypassing behavior.

Our work is similar in motivation to that of Akin and Hutchinson (1999) but uses different measures of quality. Their measures include the number of beds, number of doctors, hours open per week, drug availability and services provided. We do not question the importance of such measures, however, all of the facilities examined in our data set are rural clinics and there is little variance in these types of measures. Instead we use data collected by a medical evaluation of the clinics. Our measures of quality include the quality of consultation, and the quality of prescription. These allow us to show that, in addition to easily observable characteristics of facilities, patients appear to have a more elaborate types of information about health clinics and that they use this information to appropriately match clinics and illness conditions.

Unlike Akin and Hutchinson (1999), our work uses a facility-based sample. We visited a random sample of health facilities and drew data from a random sample of out-patient register records. We transform this data into a patient-based sample by assigning patients to the origin of their visit (their home village) and then matching them with other facilities they could have chosen to visit. Such a method is not equivalent to a household survey. It cannot examine the decision not to seek care or to seek care outside of the sample area. We have no data on the income or other personal characteristics of patients. This data would be a poor choice for an investigation of the factors that determine the choice of health provider. The richness of this data comes from the fact that we have almost 4000 patients coming from 55 villages choosing between 31 health centers that are almost identical in terms of capacity (number of doctors, beds, available drugs, etc.) but vary significantly in terms of the technical quality with which they deliver outpatient services.

We propose that these patterns of bypassing show that patients have a relatively sophisticated understanding of both the facilities they are visiting (and not visiting) and their own illness conditions. Although travel cost is a significant factor in patient choice (patients prefer to go to the closest facility), the willingness to bypass varies greatly by the illness 
condition from which they suffer. For example, patients are less likely to bypass any facility when they have suffered an injury (especially an infant) but more likely to bypass when they have an eye problem or pelvic inflammatory disease. This evidence is compatible with a view in which facilities are ranked according to an overall measure of quality and patients rank illness conditions according to an overall measure of severity. When the severity of an illness is high and the quality of the nearest center is less than that of a center further away patients will bypass the nearby facility.

However, we will show that patients' understanding of facilities and their illness conditions is more subtle and complex. When we match patient visits with our data on technical quality, the patterns of bypassing show patients behaving as if they were aware of the multidimensional quality features of health facilities and the relative importance of each of these qualities for the condition from which they suffer. Such patterns suggest that patients know the relative qualities (each facility is measured on multiple aspects of quality) of a number of different facilities. Some of the aspects of quality that we measure can be thought of as observable (attentiveness of the staff, for example), but others cannot be easily evaluated by patients (the quality of consultation). Not only do patients appear to be able to observe, or evaluate the unobservable aspects of quality, they appear to have an idea of when these qualities are more or less useful.

Patients as whole appear to seek out facilities that provide high quality consultations, facilities staffed by more knowledgeable physicians, facilities in which clinicians observe good prescription practices, and facilities in which the staff are polite. They avoid facilities that use injections too liberally or over-prescribe medication. These patterns differ significantly between illness conditions. For example, when an infant suffers from pneumonia, caretakers are less likely to seek good consultation practice, more likely to seek good prescription practice, less likely to avoid a tendency to over-use injections, but no different from the average condition in their avoidance of facilities that over-prescribe. On the other hand, when an adult suffers from pneumonia, they do not seek consultation more than the average condi- 
tion, but they do seek good prescription practice and avoid injections and over-prescription more than average.

In the following section we describe the health care system in Tanzania and Iringa Rural District. In Section 2 we outline a model of health seeking behavior in the presence of asymmetric information. In Section 3 we describe the data used to develop our empirical test. Section 4 develops the empirical model and discusses the results. Section 5 concludes.

\section{Background}

Since their entry into Tanzania in the late 19th century, church missionaries have established health facilities in the rural areas. Today, church health services contribute an almost equal number of hospital beds as the government. Church facilities are predominantly in rural areas, although in recent years churches have also opened dispensaries in urban centers. Churches are likely to play an even greater role in health delivery in the future because the government now supports the privatization of health services. Some church services that had been nationalized, such as the Kilimanjaro Christian medical center in Moshi and Bugando medical center in Mwanza, have now been returned to church control.

The training of clinical officers and clinical assistants in all government and church operated health centers takes place in government institutions. The training is standardized and clinicians have to pass examinations set by the Tanganyika Medical Training Board. External examiners are normally involved to ensure that regulations and standards set by the Board are followed. Therefore the training background of all clinical officers and clinical assistants observed in this study is the same, although some were employed in government and others are employed in church facilities.

Iringa Rural District has an estimated population of 414,000 people and a network of 67 peripheral health units that provide the primary curative care; out of these, $43(64 \%)$ are government, $17(25 \%)$ are Roman Catholic and 7 (10\%) are Lutheran. 
Government health services are highly centralized. The district hospital, led by the district medical officer (DMO), is the administrative center for all health services in the district. However, the supervision of health services in most cases leaves much to be desired because poor staffing, lack of managerial skills, and unreliable means of transport all mitigate against the DMO filling his or her mandate. The power to hire and fire staff is vested at the national level, though there is some administrative control over staff at the local level. Government health facilities are totally dependent on the centrally allocated government budget and regional and district hospitals have only recently started charging some user fees. At the time this data was collected revenue from user fees was still negligible and its use remains under central regulation due to guidelines governing it's use set by the ministry of health. Health centers and dispensaries have no control over what medicines and supplies to buy; they have to address their needs to the district level.

Lutheran health facilities fall under the Iringa diocese of the Evangelical Lutheran Church of Tanzania. The center of power is at the diocese level, exercised through the diocesan medical director. It is the diocese level, (comparable to a 'region') that makes decisions on recruitment and personnel, coordinates logistics to health facilities, and provides technical support. Unlike Lutheran services in the rest of Tanzania, Iringa region does not have a hospital which will restrain the medical director's regulatory capacity. The revenue that facilities generate through fees is pooled at the diocese and each facility maintains its account there for supply purchases and salary payments. Facilities are expected to run themselves financially, but the diocese occasionally subsidizes health centers and dispensaries.

The organization of services in the Roman Catholic facilities is the most heterogeneous. In general they are the most decentralized, but the degree of decentralization varies greatly. In fact, the heterogeneity itself is an indication of their decentralization. The diocese exercises much less influence in running the health services compared to other denominations, and in some cases there is almost none at all. Facilities recruit their own staff and salaries are set locally, except those involving staff seconded by the government, which are referred to 
the diocese. Drugs and medical supplies are purchased locally and facilities are financially independent.

\section{Our View of Health Care}

Economic theorizing about health care implicitly derives from the "medical model" of Parsons (1951, Chap. 10). Parsons saw the patient as an inadequately informed and hence passive recipient of care from an omniscient physician. Observation of patients in consultation with physicians certainly supports this view. The following summaries of conversations with Lebanese women encapsulates the near-universal experience of health-seeking.

Lebanese women's perception of the obstetric care they received was characterized by the feeling of passivity. ... [W]omen are often very cooperative with the medical team in a hospital setting and don't express their concerns and worries. ... No woman reported that she had actively challenged any procedure or aspect of care she received. (Kabakian-Khasholian et al., 2000, pp. 111-112)

Health care is a classic example of hidden effort or what is referred to as agency in health care economics (Arrow, 1963, 1986; Dranove and White, 1987; Mooney and Ryan, 1993; Gaynor, 1994; McGuire, 2000). Patients choose to visit physicians precisely because physicians know more than patients. The patient cannot easily evaluate what the doctor is doing for her sake, and would therefore be hard-pressed to interfere with his expertise during a medical procedure or even consultation.

However, though patients are passive, they are not necessarily ignorant.

Despite their passivity, when women were asked directly, they expressed their dissatisfaction with many of the procedures during pregnancy, labor and delivery. (Kabakian-Khasholian et al., 2000, pp. 111-112)

If they are dissatisfied, why don't they say anything? They appear to have information, but are not using it during the consultation. What is the point of this information? 
[W]omen based their choice of provider on their previous experience with the same physician or on what they heard from other women in their social network. (Kabakian-Khasholian et al., 2000, p. 106)

Patients have a choice about who they visit and even though they appear to be - and certainly act - powerless when face to face with a physician, there is no reason for them to be powerless when they choose a physician.

It is the premise of this paper that patients cannot negotiate with practitioners in the course of their treatment but they can use information to choose the correct practitioner. The empirical literature on health care in Africa demonstrates quite conclusively that the sick are not passive in their use of the health care system but instead are actively making choices between an array of options. The choices made often are explained by factors unrelated to medicine, such as price and distance, or by static attributes of the facilities, such as availability of drugs or perceived quality (Stock, 1983; Nougtara et al., 1989; Yoder, 1989; Waddington and Enyimayew, 1989; Abel-Smith and Rawal, 1992; Omorodion, 1993; Litvack and Bodart, 1993). None of these factors contradict the image of the sick as passive recipients of health care from providers whose methods of operation are obscured in a 'black box.' Another group of studies, however, indicates that choice is being guided by the character or severity of the illness (Mwabu, 1986; Sauerborn et al., 1989; Bichmann et al., 1991; Leonard, 2000a,b,c; Ndeso-Atanga, 2000). As a group this body of research suggests that the sick may be less ignorant about the kinds of medical treatment they require than the traditional medical model has implied.

Our view of health seeking differs from traditional models in the following ways. First, an illness is itself a production function. A combination of the same inputs will produce a different expected gain in health depending on the illness condition. Some conditions are very responsive to diagnostic effort, others to medication, and still others to equipment or training. Ideally, when patients fall ill from different conditions they will seek different combinations of inputs. We might expect patients to enter the market place seeking unique 
packages of inputs that reflect the trade-off between the marginal productivity of an input (in terms of the value obtained from an increased probability of being cured from a utilitydebilitating illness) and its marginal cost. However, this depends crucially on the ability of patients to negotiate over the quantity and quality of goods that are delivered.

The second feature of our view of health care is the reason why we do not observe patients seeking out any provider and ensuring all necessary inputs are delivered. Many of the most important inputs in health care - diagnostic effort, for example - suffer from asymmetric information. Patients cannot assess the appropriateness and quality of the activities of their practitioners. Patients cannot go to a practitioner and form a contract for the delivery of diagnostic effort because they would not know whether or not it was provided. Patients' only information on the quality of care is whether or not they were cured, and it is possible to be cured despite bad care or not cured despite good care.

Third, African patients are seeking this valuable good that suffers from asymmetric information in an environment in which regulatory and institutional guarantees of quality differ greatly from organization to organization. For the institution of modern medicine we suggest that most quality assurance comes from hierarchical supervision (for discussion, see Leonard, forthcoming) and that quality is a function of the organizational form of the health facility in question. It can therefore reasonably be viewed as exogenous from the point of view of the patient. In the absence of asymmetric information quality would be a function of the real or perceived needs of the patient.

\subsection{A model of health seeking behavior}

To form a model of health seeking behavior these observations lead to the following assumptions about the information patients possess. Patients cannot evaluate many important aspects of quality at the time they are being delivered, nor can they use outcomes as proxies for the quality that is delivered since outcomes are discrete and subject to significant stochastic disturbance. Thus, they cannot contract with physicians over the quality that will be 
delivered. Instead quality is a function of features outside of patient's control. Patients have an expectation of the level of quality that will be provided. This expectation is then used in deciding which facility to visit. Patients have an understanding of which aspects of quality are more important for which illnesses, and when they suffer from an illness that they believe is highly responsive to a particular type of quality, they are more likely to seek a facility that they believe can provide that quality.

We use the following representation of the value of health care:

$$
\Delta E U=W h-C
$$

where $\triangle E U$ is the expected change in utility from seeking health care, $\mathrm{w}$ is the value of "healthiness", $\mathrm{h}$ is the expected "quantity" of healthiness, and $C$ are costs (see Leonard, $2000 \mathrm{~b}$, for a more deliberate derivation of this equation). Healthiness is easiest thought of as a quantity that increases the probability of being cured. As the quantity of health consumed increases, the probability of being cured increases.

An ideal model of the expected utility from visiting any given provider would take the following form,

$$
\Delta E U_{i j k}=W_{i}\left(\prod_{l=1}^{L}\left(R_{j k}^{l}\right)^{\alpha_{l k}}\right)-F_{j k}-T_{i j}
$$

with the variables in Equation 2 defined in Table 1.

Table 1: Definitions of Terms in Equation 2

\begin{tabular}{r|l} 
variable & definition \\
\hline$i$ & Index of individuals \\
$j$ & Index of providers (nearest government, Lutheran or Roman Catholic) \\
$k$ & Index of illness conditions (cough, diarrhea, injury, etc.) \\
$l$ & Index of resources (diagnostic effort, quality prescription, etc.) \\
$\Delta E U$ & Net expected utility \\
$W$ & Value of healthiness \\
$R_{j k}^{l}$ & Quantity of resource $l$ available at provider $j$ for illness condition $k$ \\
$\alpha_{l k}$ & Responsiveness of illness condition $k$ to resource $l$ \\
$F_{j k}$ & Expected fee and drug costs of illness condition $j$ at provider $k$ \\
$T_{i j}$ & Travel cost of individual $i$ to provider $j$
\end{tabular}


$\prod_{l=1}^{L}\left(R_{j k}^{l}\right)^{\alpha_{l k}}$ represents the expected quantity of health care delivered by a particular health facility. In general we might expect health care to be a function of the technical quality of diagnosis (including consultation, examination and laboratory tests) or prescription, skill, health education, etc. The greater the inputs provided, the greater the quantity of health care consumed and the greater the probability of being cured. Though this specification seems very general, it assumes that each resource available at each facility is fixed for each illness condition. In the absence of asymmetric information the patient would seek to consume each resource until its marginal benefit was equal to its marginal cost. Here patients can only choose between facilities with different menus of resources available, not what to consume at each facility.

Our data allows us to observe the choice that patients make, and therefore develop a picture of their relative valuation of different health facilities. It is important to note here that one of the more unfortunate realities in African health care, the absence of formal health insurance, is useful to this exercise. Health insurance usually ties a patient to one particular facility (or introduces an additional cost if patients choose not to visit their primary facility). Patients with health insurance would choose between health insurance providers by trying to predict all of the illnesses they were likely to experience in the coming year (or the time period within which switching health insurance plans is prohibitive) and then visit their primary care provider for each illness even if it would not have otherwise have been the optimal choice. In Africa, and in Tanzania, without health insurance, patients can (and do) choose a different provider for each and every illness condition and for each and every member of the family.

If we knew $W, R, F$ and $T$ we would simply estimate the matrix $\alpha$. However, our data is not rich enough for this approach. We have no measure of $W$, nor do we have the variables that might help us estimate it such as income, occupation, education, etc. In addition, we do not have any estimate of $F$. Thus, rather than estimate the form of the model represented 
in Equation 2, we will concentrate on the following form of the model:

$$
\Delta E U_{i j k}=\left(\sum_{l=1}^{L} R_{j}^{l} \cdot \tilde{\alpha}_{l k}\right)-\tilde{F}_{j k}-\tilde{T}_{i j}
$$

This specification can be estimated with the data that we have, and fits a linear model that can be estimated with a conditional logit. We will assume that expected costs (in fees and drug costs) are an institutional/illness condition constant. Thus, patients assume that cost varies between institutions and between illness conditions but does not vary within institutions (different facilities that have the same owner). $\tilde{\alpha}$ is not equivalent to the $\alpha$ of Equation 2, but is a crude indicator of the importance of a resource in the care of a particular illness condition. We will return to this model and the empirical issues it might involve in Section 4.

\section{Data}

There are four data sets used in this paper. The first is a study undertaken by Dr. Mpuya, (the DMO for Iringa Rural district) with the assistance of the Collegio Universitario Aspiranti e Medici Missionari (CUAMM). The data is referred to as OPD SQA (OPD Service Quality Assessment). A random sample of health centers (RHC) and dispensaries was visited and consultations were observed and assessed for quality. In addition, all medical officers sat an exam and data was collected on the availability of medicines and the appropriateness of prescriptions. From this data we will be able judge many aspects of the quality of care available at a number of facilities in the district.

K. Leonard joined the above mentioned data collection effort and took a random sample of out-patient registry entries from the registries for 1994. The patient registry records the age and gender of the patient, the presenting symptoms or diagnosis, the medicines prescribed and the home village of the patient. Entries were randomly sampled from each month of the year. This data is referred to as the OPD RR. 
Dr. Mliga conducted a separate assessment of the quality of out-patient services in Iringa (rural and urban) as well as Arusha region. The process for collecting data is similar to that of the OPD SQA, but each center is matched to a data set on the organizational practices of the center and the institution that manages that center. This data is referred to as DQA (Decentralization and Quality Assessment). The major findings of this data set are available in published form (Mliga, 2000).

An additional data set comprises the annual reports (on Ministry of Health form F006) of each health facility in the Iringa Rural district. These forms contain the total number of patients presenting with a wide variety of diagnoses. The only additional designation is by whether the patient was younger than 5 or 5 and older. We refer to this data as the Annual Health Center Reports (AHCR). We use the AHCR to properly weight our regressions to control for the fact that choice-based sampling is a type of stratified random sampling.

\subsection{OPD Service Quality Assessment (OPD SQA)}

In this data set we find direct evidence for the theory that there is asymmetric information in the provision of medical effort - that clinicians will shirk in the absence of strong incentives to provide unobservable effort. At each center a large number of consultations (approximately 40 per clinician) were observed by a clinician who was a member of the evaluation team. The clinician was judged according to a number of discrete actions, where the physician either performed or failed to perform the action. The consultation score is based on specific actions necessary for effective diagnosis or treatment of the presenting condition. If the clinician scored a zero for a particular action he failed to do what was medically required by the patient's condition. The very fact that what is medically required differs by presenting condition and by the answers to previous questions is a source of asymmetric information. The evaluator's checklist already surpasses the information available to the average patient.

Failure to perform a required action might suggest ignorance rather than shirking, but the data dispels this particular hypothesis. Each clinician sat a written exam. Some of the 
questions correspond directly to the actions expected of clinicians in the consultations. If the clinician got the correct answer on the exam, he knew what he was supposed to do in the consultation. There were a total of 7 consultation action / exam question pairs. Table 2 shows the correlation between knowledge and practice for these 7 actions. $41 \%$ of the time a doctor knew what to do and did it. $59 \%$ of the time he knew what he should do but did not. Most clinicians knew what to do, but this did not always lead them to do the right thing. However, since our data contains clinicians who did not know what to do and only luck leads these clinicians to do the right thing, knowing what to do is positively correlated with doing the right thing.

Table 2: Correlation between knowledge and use of procedure

\begin{tabular}{l||c|c||r}
\multicolumn{1}{c||}{} & \multicolumn{2}{c||}{ Test Answer } & \\
Use & incorrect & correct & \\
\hline Incorrect & 67 & 442 & 509 \\
column \% & $72 \%$ & $59 \%$ & $60 \%$ \\
Correct & 26 & 313 & 339 \\
column \% & $28 \%$ & $41 \%$ & $40 \%$ \\
\hline & 93 & 755 & 848
\end{tabular}

What factors cause clinicians to do the right thing? Clinicians at Roman Catholic facilities perform statistically superior examinations compared to their colleagues at Lutheran and government facilities. However, there are differences even between centers of the same institutional affiliation and we have information about other factors of the center that will help explain performance. Table 3 shows the effect of rank, number of supervision visits, experience, workload, satisfaction, exam score, institutional affiliation and whether the consultation in question is one of the first two consultations we observed for that presenting condition.

Note that the significance of the first two visits is important. Since clinicians are being observed by their peers it is hard to believe their behavior is not effected. Does a clinician behave the same when he is alone with a patient as he does when he is being observed? Inspection of the scores for each clinician shows a large drop off in the scores as we continue 
Table 3: Explaining Adjusted Consultation Scores

\begin{tabular}{|c|c|c|}
\hline $\begin{array}{l}\text { Dependent Variable is } \\
\text { Adjusted Consultatio }\end{array}$ & Score & \\
\hline Independent variable & Coef & z-test \\
\hline constant & -2.27 & -1.943 \\
\hline rank & .42 & 1.292 \\
\hline \#of supervision visits & .74 & 3.056 \\
\hline experience & -.03 & -1.626 \\
\hline workload & -.04 & -3.227 \\
\hline Roman Catholic & -.24 & -0.715 \\
\hline Lutheran & -.75 & -1.150 \\
\hline Exam score & .13 & 2.928 \\
\hline first two observations & .51 & 2.657 \\
\hline job satisfaction & .62 & 3.198 \\
\hline
\end{tabular}

to observe. There is a significant difference between the scores of the first two observations (per presenting condition) and the subsequent scores - clinicians rapidly adjust to the presence of observers. This, again, is evidence of shirking - clinicians are aware of what they are supposed to do, but find the extra effort required to do so rapidly exhausts their new-found enthusiasm for quality.

It is important to note that experience does not affect the consultation score; the coefficient is both small and statistically insignificant. A concern of this data collection effort was that experience would lower the consultation score. Doctors maintain that experience allows them to skip steps in diagnosing patients without compromising quality. An unsophisticated instrument would mistakenly penalize experienced doctors.

Increasing the number of supervision visits increases quality, as should be expected. An increased workload (number of patients) lowers quality and satisfaction increases quality. Clearly, workload and satisfaction are not purely exogenous variables, but combined with the frequency of supervision and the exam score they appear to explain the difference between Roman Catholic, Lutheran and government facilities. 


\subsection{Decentralization and Quality Assessment (DQA)}

The DQA survey matches measures of technical quality that are similar to the OPD SQA survey to data on the organizational structure of the facilities in question. Mliga (2000) examines the organizational structure of 3 different NGO health systems as well as the government system. ${ }^{3}$ The variety of organizational form within church health systems permits an investigation into which features are most correlated with quality. We reproduce here the tabulated summary of findings of Mliga (2000). Decentralized control over staffing decisions (STAFF CONTROL) increases the diagnostic effort (DIAGNOSIS), appropriate use of labs (LAB), effort in health education (EDUCATION), and attentiveness (ATTENTIVE) while it decreases the appropriateness of prescriptions (PRESCRIP). However, decentralized control of resources and financing such as drug purchasing and the level of fees (RESOURCES CONTROL) does not lead to an increase of any of these quality measures.

Table 4: Regression on Performance Measures of Decentralization

\begin{tabular}{|c|c|c|c|c|c|}
\hline \multirow[b]{2}{*}{ Independent Variable } & \multicolumn{5}{|c|}{ Dependent Variable } \\
\hline & DIAGNOSIS & LAB & EDUCATION & ATTENTIVE & PRESCRIP \\
\hline $\begin{array}{l}\text { STAFF CONTROL } \\
\text { RESOURCE CONTROL }\end{array}$ & $0.150 \ddagger$ & $0.208 \ddagger$ & $0.203 \ddagger$ & $\begin{array}{c}0.373 \dagger \\
-0.129 \ddagger\end{array}$ & $-0.117 \dagger$ \\
\hline
\end{tabular}

An important implication for this study is that those qualities of a center that increase DIAGNOSIS, LAB, EDUCATION and ATTENTIVE decrease the quality of prescriptions in the center. Good incentives decrease shirking but they also increase the incentive to profit from the sale of pharmaceuticals.

\subsection{OPD Register Records (OPD RR)}

The registers contain a variety of different types of information but they all include the patient's age, the village she traveled from, the presenting conditions (mixed with diagnoses)

\footnotetext{
${ }^{3}$ By collecting data in Arusha region as well as Iringa, the Seventh Day Adventist church was included in the sample. There are no SDA facilities in Iringa, and thus we concentrate on only 2 NGO health systems.
} 
and the drugs prescribed (including the form of the drug). We will be using the village information as well as the presenting condition or conditions, the number of drugs prescribed and, for adults with malaria, whether or not they received an injection.

\subsection{Constructing a Data Set}

A random sample of patients at a random sample of providers is a stratified random sample. With knowledge of the stratification we can view each observation as representing an independent observation of a patient choosing to visit a particular center. Our goal is a data set that matches a patient's choice of health care practitioner to data about

- the individual

- the center the patient chose to visit (including travel cost and measures of quality)

- the centers the patient chose not to visit (including travel cost and measures of quality)

- the illness condition from which the patient suffered

We simplify the range of choice by assuming that patients choose between the nearest government center, the nearest Roman Catholic center and the nearest Lutheran center. The patient register contains data about the patient's age and gender and home village as well as the presenting condition. Since the register entries were taken from centers sampled for the OPD SQA survey we have data on various measures of quality in the center visited. For each patient we find their home village and assign to that data the nearest centers of the two types not visited. Thus if we visited a government center and sampled a patient register showing a person came from particular village, we find the Roman Catholic and Lutheran centers closest to that village and assign these as alternative choices. In some cases those centers were also evaluated by the same survey, so we have matching data for choices made and not made. In other cases the alternative choices were evaluated by the DQA survey. The two surveys collected similar data on consultation quality and attentiveness, and overlapped 
for 7 centers. Using both surveys for the 7 overlapped centers we can adjust the scores so they match each other. The fit was good. Where there was overlap we average the adjusted scores, where there was no overlap we use only the corresponding adjusted score. For some centers there was no quality assessment at all. For these centers we take the average quality for that type of center (where type varies by ownership and level (dispensary or RHC)) Thus every center has a range of quality scores assigned to it.

The quality scores assigned to centers were

TEST SCORE: The average exam score of all clinicians at any given center. This data comes from the OPD SQA survey and non-sampled centers were assigned the average score for their type of center.

CONS SCORE: The average quality of consultations from the point of view of the observing clinician. This comes from both the OPD SQA survey and the DQA survey. These scores are corrected for the influence of the first couple of observations by regressing consultation score against consultation number and assigning a fixed effect to each clinician. The CONS SCORE of each facility is the average of the fixed effects for each of its clinicians.

ATTENTIVENESS: The politeness of the clinician, including greeting and making sure the patient is comfortable as well as explaining diagnoses and asking if the patient understood.

PRESCRIPTION: This score reflects the appropriateness of the prescriptions given to patients. The 'perfect' prescription involves only the necessary drugs and all the necessary drugs. If too many drugs were prescribed the score falls, but less than if a necessary drug is missing or a dangerous interaction is included. This data comes from the OPD SQA survey.

MALARIA INJ: The percentage of non-infant prescriptions for malaria that were given by injection. An injection for an adult with malaria is almost never indicated, even if 
the condition is severe. However, patients are often impressed by injections and might prefer them. This is a per-facility average from the OPD RR. If an adult has malaria and is seeking care, this variable directly impacts on the probability that she will get an injection. However, we intend this variable to reflect a proclivity to injections in general; if a facility will use injections when they are not indicated, they are more likely to use them in all cases.

NUM DRUGS: Number of drugs prescribed. Unlike PRESCRIPTION, this is not necessarily in conflict with the health of patients, but inflicts unnecessary costs. Again this is a per-facility average from the OPD RR.

Lutheran facilities give three times as many injections to non-infants with malaria as government facilities, and Roman Catholic facilities almost twice as many. Government facilities prescribe 1.4 drugs per condition on average, Roman Catholic facilities prescribe 1.5 and Lutheran facilities prescribe 1.9 on average. Both measures are ways of collecting more money for the center, so it is not surprising that they behave in this manner.

The final requirement to create a data set is to weight it according to the sampling procedure. We do not have a random sample of patients, but a random sample of locations; choice-based sampling. A correction for the procedure requires that each observation be weighted by the ratio of the fraction of the total population of patients choosing a given location to the faction of the sample population of patients choosing that location (Maddala, 1983, pp. 76). The AHCR data gives us the total number of patients that visited each center in a year, and from this we can know what proportion of visitors to that center was actually sampled and weight the sample.

There are a total of 3,936 observations in this data set representing register data collected from 17 health centers of which 11 are government, 4 are Roman Catholic and 2 are Lutheran. The patients come from 55 villages and face choices between a total of 17 government, 8 Roman Catholic and 6 Lutheran facilities. Of the facilities between which patients can choose we have quality data on 10 of the 17 government facilities 4 of the 8 Roman Catholic 
and 2 of the 6 Lutheran facilities. Where we have no quality data we use averages of the known facilities of the same institutional affiliation and type. ${ }^{4}$

\section{Analysis}

Our goal in this section is to let the data tell us why people are willing to travel further than necessary, what resources they are seeking, and when they seek them. To this end we develop a mixed multinomial and conditional logit model to explain the choice of health center by patient.

As a first step we develop a list of illness conditions that we will track. Table 5 shows the prevalence of illnesses in our sample. The definition of an illness condition is of crucial importance. We want to group all illnesses and symptoms in categories that patients would be able to differentiate. They may not know the diagnosis, but they should be able to differentiate a set of symptoms in one illness condition from a set of symptoms in another illness condition. Thus, though a patient may not know if they have pneumonia they should know that they suffering from a condition that is distinct from an upper respiratory tract infection, or a cough. In addition, we want to avoid the problem of mis-diagnoses. One condition may be assigned a different diagnosis in different facilities. If a Roman Catholic clinic calls a set of symptoms bronchitis and a government clinic calls it a common cold we do not want to consider these separate illness conditions. The list of all symptoms and diagnoses and how they fit into the shorter list shown in Table 5 is shown in Table 13 in Appendix A. We track the top 12 illness categories for both infants and non-infants.

\footnotetext{
${ }^{4}$ The use of averages instead of actual measures (especially in the case of Lutheran facilities) is an unfortunate limitation of the data set. However, since the facilities were randomly chosen this does not introduce bias.
} 


\begin{tabular}{|c|c|c|c|c|c|c|}
\hline condition & $\begin{array}{l}\text { le } 5: \\
\text { i } \\
\text { \# }\end{array}$ & $\begin{array}{l}\text { ness } C \\
\text { ant } \\
\%\end{array}$ & $\begin{array}{l}\text { ditio } \\
\text { nor } \\
\#\end{array}$ & $\begin{array}{l}\text { Prevale } \\
\text { nfant } \\
\%\end{array}$ & \# & $\begin{array}{r}\text { tal } \\
\%\end{array}$ \\
\hline malaria & 555 & $44.9 \%$ & 897 & $31.5 \%$ & 1452 & $35.6 \%$ \\
\hline upper rti & 133 & $10.8 \%$ & 287 & $10.1 \%$ & 420 & $10.3 \%$ \\
\hline pneumonia & 143 & $11.6 \%$ & 225 & $7.9 \%$ & 368 & $9.0 \%$ \\
\hline cough & 117 & $9.5 \%$ & 198 & $6.9 \%$ & 315 & $7.7 \%$ \\
\hline injury & 44 & $3.6 \%$ & 234 & $8.2 \%$ & 278 & $6.8 \%$ \\
\hline diarrhea & 66 & $5.3 \%$ & 119 & $4.2 \%$ & 185 & $4.5 \%$ \\
\hline dysentery & 32 & $2.6 \%$ & 128 & $4.5 \%$ & 160 & $3.9 \%$ \\
\hline eye problem & 58 & $4.7 \%$ & 69 & $2.4 \%$ & 127 & $3.1 \%$ \\
\hline worms & 21 & $1.7 \%$ & 72 & $2.5 \%$ & 93 & $2.3 \%$ \\
\hline scabies & 37 & $3.0 \%$ & 42 & $1.5 \%$ & 79 & $1.9 \%$ \\
\hline severe abdominal pain & 4 & $0.3 \%$ & 75 & $2.6 \%$ & 79 & $1.9 \%$ \\
\hline pelvic inflammatory disease & 2 & $0.2 \%$ & 52 & $1.8 \%$ & 54 & $1.3 \%$ \\
\hline sores / abscess & 22 & $1.8 \%$ & 27 & $0.9 \%$ & 49 & $1.2 \%$ \\
\hline skin infection & 4 & $0.3 \%$ & 44 & $1.5 \%$ & 48 & $1.2 \%$ \\
\hline ear problem & 20 & $1.6 \%$ & 19 & $0.7 \%$ & 39 & $1.0 \%$ \\
\hline sexually transmitted disease & 2 & $0.2 \%$ & 36 & $1.3 \%$ & 38 & $0.9 \%$ \\
\hline asthma & 1 & $0.1 \%$ & 36 & $1.3 \%$ & 37 & $0.9 \%$ \\
\hline toothache/cavity & 0 & $0.0 \%$ & 28 & $1.0 \%$ & 28 & $0.7 \%$ \\
\hline chest/heart pain & 5 & $0.4 \%$ & 21 & $0.7 \%$ & 26 & $0.6 \%$ \\
\hline arthritis & 1 & $0.1 \%$ & 19 & $0.7 \%$ & 20 & $0.5 \%$ \\
\hline
\end{tabular}

52 represents a tracked illness

\subsection{Illness Condition-Specific Distance Gradients}

Before we move to our model we show the results of a mixed multinomial logit and conditional logit model in which the expected cost varies only with the institution, gender and age, and patients have a willingness to travel that varies by illness condition. Table 6 contains the results of a regression in which the conditional coefficients include an interaction between each of the non-infant and infant illnesses we are tracking and the travel cost to each provider. The sum of the coefficient on the interaction term and the coefficient for travel distance represents an illness condition-specific travel coefficient. A positive coefficient for an illness condition/travel interaction means that, for that illness, patients are relatively more willing to incur travel costs. 
Table 6: Illness Specific Willingness to incur Travel Costs

\begin{tabular}{|c|c|c|c|c|c|c|}
\hline \multirow[b]{2}{*}{ Multinomial var. } & \multicolumn{4}{|c|}{ R. Catholic Lutheran } & & \\
\hline & Coef. & $z$-tes & t Coef. & $z$-test & & \\
\hline constant & $\begin{array}{c}-0.736 \\
\end{array}$ & -1.26 & -0.630 & -0.93 & & \\
\hline age (years) & -0.010 & -0.61 & -0.036 & -1.80 & & \\
\hline infant $(0-5)$ & 2.114 & 3.55 & 1.839 & 2.73 & & \\
\hline ild & 0.407 & 0.60 & -0.486 & -0.60 & & \\
\hline 16) & -1.137 & -1.79 & -1.321 & -1.76 & & \\
\hline female & -0.147 & -0.50 & -0.377 & -1.18 & & \\
\hline \multirow{2}{*}{\multicolumn{3}{|c|}{$\begin{array}{l}\text { Illness/travel interaction terms } \\
\text { Conditional var. }\end{array}$}} & \multicolumn{2}{|c|}{ Infants } & \multicolumn{2}{|c|}{ Non-Infants } \\
\hline & & & Coef. & z-test & Coef. & z-test \\
\hline \multicolumn{3}{|l|}{ malaria } & -0.082 & -2.27 & $\begin{array}{c}-0.132 \\
\end{array}$ & -3.29 \\
\hline \multicolumn{3}{|l|}{ upper rti } & 0.130 & 2.96 & -0.289 & -3.32 \\
\hline \multicolumn{3}{|l|}{ pneumonia } & -0.035 & -0.70 & -0.236 & -2.75 \\
\hline \multicolumn{3}{|l|}{ cough } & -0.054 & -1.05 & -0.084 & -1.41 \\
\hline \multicolumn{3}{|l|}{ injury } & -0.860 & -2.31 & -0.296 & -3.29 \\
\hline \multicolumn{3}{|l|}{ diarrhea } & 0.013 & 0.18 & -0.128 & -1.14 \\
\hline \multicolumn{3}{|l|}{ dysentery } & 0.014 & 0.17 & 0.121 & 2.74 \\
\hline worms & & & 0.034 & 0.37 & -0.255 & -1.91 \\
\hline \multicolumn{3}{|l|}{ eye problem } & -0.146 & -1.56 & 0.195 & 4.48 \\
\hline \multicolumn{3}{|l|}{ scabies } & -0.345 & -2.22 & & \\
\hline \multicolumn{3}{|l|}{ sores/abscess } & -1.145 & -1.46 & & \\
\hline \multirow{2}{*}{\multicolumn{3}{|c|}{$\begin{array}{l}\text { ear problem } \\
\text { severe abd pain }\end{array}$}} & -0.292 & -1.38 & & \\
\hline & & & & & -0.077 & -0.86 \\
\hline \multicolumn{3}{|l|}{ Pelvic Infl. Dis. } & & & 0.136 & 2.10 \\
\hline \multirow{2}{*}{\multicolumn{3}{|c|}{ skin inf. }} & & & -0.170 & -1.25 \\
\hline & & TRAVEL DIST & -0.300 & -11.60 & & \\
\hline
\end{tabular}

log likelihood $=-2036.42$

Mixed conditional/multinomial logit regression. Dependent variable is choice of institution (government, Roman Catholic and Lutheran). Multinomial coefficients on gov. normalized to zero. Positive (negative) coefficient on illness condition/travel interaction term implies travel cost is less (more) prohibitive than for the average condition. 
A possible explanation of the behavior reflected in this regression is that specific illnesses are more severe than others and that the relative importance of distance expands or contracts depending on the illness condition. Both Stock (1983) and Kloos (1990) discuss the illness condition-specific distance gradient observed in their data. Illnesses can be thought of as representing a topographical contraction or expansion of the patient's local area. Some illnesses make distances shorter, and others make distances further. Note that no illness achieves a zero coefficient (a complete compression of distances) - patients always prefer to avoid travel.

For infants malaria, injuries and scabies increase the importance of travel whereas an upper respiratory tract infection decreases the importance of travel. For non-infants malaria, upper respiratory tract infection (URTI), pneumonia and injury increase the importance of travel and dysentery, eye problems and pelvic inflammatory disease (PID) decrease the importance of travel. Topographically speaking, a person with an eye problems sees the world as almost two thirds more compact than the average patient, whereas when an infant has an injury the world is 3 times more spread out. When a high quality location is only a little bit further than a low quality location the non-infant with an eye problem pays a low addition cost to bypassing, but the infant with an injury faces high additional costs.

\subsection{Testing for Patient Knowledge of Resource Availability}

Although the illness-specific gradient is an interesting view it does not represent the behavior we seek to model or understand. Recall the model we seek to estimate,

$$
\Delta E U_{i j k}=\left(\sum_{l=1}^{L} R_{j}^{l} \cdot \tilde{\alpha}_{l k}\right)-\tilde{F}_{j k}-\tilde{T}_{i j}
$$

The patient is choosing between the nearest government, Lutheran and Roman Catholic facilities $(k \in\{G, R C, L\})$. The estimated cost is a fixed cost per institution (which can vary by individual characteristics such as age or gender) plus an institution / illness condition 
dummy variable. That the fee could vary by gender or age, is not to suggest that every patient would face a different expected cost, but that the same illness conditions in different age groups might have different expected costs. These differences turn out not to be significant.

$$
\tilde{F}_{j k}=\underbrace{F_{j}^{0}}_{\text {const }}+\underbrace{F_{j}^{1} \cdot x_{1} \ldots F_{j}^{n} \cdot x_{n}}_{\text {ind. characteristics }}+\underbrace{F_{j}^{n+1} \cdot x_{n+1} \ldots F_{j}^{n+m} \cdot x_{n+m}}_{\text {illness conditions }}
$$

$x^{n+1} \ldots x^{n+m}$ are a collection of dummy variables representing illness conditions for infants and non-infants. To solve the model we normalize the coefficients for fees at government facilities to zero. The estimated travel cost is just a function of the travel distance.

$$
\tilde{T}_{i j}=T_{i j} \cdot t
$$

where $T_{i j}$ is the travel distance and $t$ is a scalar that is constant for the whole data set. $\tilde{\alpha}_{l k}$ are estimated for each illness condition / resource combination, except that we do not interact politeness or test score with illness condition.

This leads to an empirical model which is a mixture of the multinomial and the McFadden conditional logit (Maddala, 1983, p. 44). The log likelihood is as follows:

$$
\begin{gathered}
\log L=\sum_{i=1}^{N} \sum_{j \in\{G, R C, L\}} \delta_{i j} \log P_{i j} \\
\text { where } \quad P_{i j}=\frac{\exp \left(\Delta E U_{i k}\right)}{\sum_{m \in\{G, R C, L\}} \exp \left(\Delta E U_{i k}\right)}
\end{gathered}
$$

where $\delta_{i j}=1$ when patient $i$ chose provider $j$ and 0 otherwise.

\subsubsection{Results}

The results of the estimation of Equation 6 with utility defined as in Equation 3 are shown in Table 7 (continued as Table 8). ${ }^{5}$ We focus here on whether or not the coefficients on the

\footnotetext{
${ }^{5}$ Since most of the variables are dummy variables and neither the distance nor estimated cost can easily be represented as money amounts we do not show a table of marginal impacts; there is little value to examining
} 
Table 7: Predicting Visits with Illness Condition / Resource interactions (cont. as Table 8)

\begin{tabular}{|c|c|c|c|c|c|c|c|}
\hline \multirow[b]{2}{*}{ Multinomial Coef. } & \multicolumn{2}{|c|}{ R. Catholic } & \multicolumn{2}{|c|}{ Lutheran } & \multirow[b]{3}{*}{ Conditional Coef. } & \multirow[b]{3}{*}{ Coef. } & \multirow[b]{3}{*}{ z-test } \\
\hline & Coef. & z-test & Coef. & z-test & & & \\
\hline constant & -4.813 & -5.55 & - -0.840 & $\begin{array}{c}-0.82 \\
\end{array}$ & & & \\
\hline age $(y$ & -0.023 & -1.19 & -0.018 & -0.76 & TRAVEL DIST & 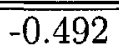 & -24.59 \\
\hline & 0.319 & 0.28 & 1.852 & 1.45 & TEST SCORE & 4.016 & 17.60 \\
\hline chil & 1.016 & 1.25 & 0.134 & 0.14 & ATTENTIVENESS & 2.172 & 5.75 \\
\hline youth $(10-16)$ & -1.153 & -1.54 & -1.384 & -1.61 & & & \\
\hline female & -0.267 & -0.74 & -0.549 & -1.43 & & & \\
\hline
\end{tabular}

\begin{tabular}{|c|c|c|c|c|c|c|c|c|}
\hline \multirow[b]{2}{*}{ variable } & \multicolumn{2}{|c|}{ R. Catholic } & \multicolumn{2}{|c|}{ Lutheran } & \multicolumn{2}{|c|}{ R. Catholic } & \multicolumn{2}{|c|}{ Lutheran } \\
\hline & Coef. & $z$-test & Coef. & z-test & Coef. & z-test & Coef. & z-test \\
\hline malaria & 8.215 & 5.69 & 16.006 & 9.36 & 9.781 & 8.19 & 17.907 & 11.27 \\
\hline uppe & 5.702 & 2.80 & 7.067 & 2.72 & 4.007 & 1.39 & 9.380 & 3.15 \\
\hline pneu & -8.952 & -2.13 & -13.707 & -1.90 & 0.421 & 0.12 & -3.061 & -0.54 \\
\hline coug & .014 & 3.4 & 20.951 & 4.2 & 10.367 & 4.08 & 15.676 & 4.97 \\
\hline & .698 & 1.61 & 59.580 & 1.34 & 14.507 & 7.28 & 13.846 & 4.88 \\
\hline di & 28.034 & 3.97 & 37.337 & 2.49 & 5.739 & 1.48 & 16.810 & 2.71 \\
\hline & 916 & 1.2 & 0.650 & 0. & 12.700 & & 20.732 & 7.64 \\
\hline & 3.531 & -0.26 & 12.189 & 0.3 & 10.608 & 0.93 & 1.134 & 0.07 \\
\hline blem & 14.828 & 3.1 & 20.096 & 3.03 & 3.236 & 0.96 & 10.427 & 2.48 \\
\hline scabi & 3.758 & 0.54 & 2.923 & 0.27 & & & & \\
\hline sores/abscess & -0.360 & -0.02 & -8.279 & -0.27 & & & & \\
\hline & & & & & 12.626 & 4. & 20.097 & 4.57 \\
\hline & & & & & 10.573 & 2. & 18.384 & 1.62 \\
\hline skin & & & & & 3.745 & -0.91 & -13.605 & -1.90 \\
\hline
\end{tabular}

interaction terms are significant. The collection of interaction terms is highly significant (the $\mathrm{p}$-value of test of restriction is 0.00 ). Travel distance is a very important factor in the choice of health care provider. Patients do not bypass facilities without good reason.

Table 9 is a summary of the coefficients in Table 8 . Significant coefficients are shown with either,+++ or,--- , where ++ and - - are coefficients significant at the $5 \%$ level and + and - are coefficients significant at the $10 \%$ level. Clearly illness condition / resource interactions are an important determinant of the choice of health care provider.

The logic of the patterns observed in this data are discussed in detail in the following section, however it is an important finding that these patterns exist. It suggest that patients the magnitude of the coefficients. 
Table 8: Predicting Visits with Illness Condition / Resource interactions (cont. from Table 7)

\begin{tabular}{|c|c|c|c|c|c|c|c|c|}
\hline & \multirow{2}{*}{\multicolumn{2}{|c|}{$\begin{array}{l}\text { CONS SCORE } \\
\text { Coef. z-test }\end{array}$}} & \multirow{2}{*}{\multicolumn{2}{|c|}{ MALARIA INJ }} & \multicolumn{2}{|c|}{ PRESCRIPTION } & \multicolumn{2}{|c|}{ NUM DRUGS } \\
\hline & & & & z-test & Coef. & z-test & Coef. & $z$-test \\
\hline & \multicolumn{8}{|c|}{ Infants } \\
\hline malaria & 855 & $\overline{5.29}$ & -5.621 & -7.15 & $\overline{3.100}$ & $\overline{6.30}$ & -3.675 & -4.73 \\
\hline & & -1.04 & & 0.05 & 0.886 & 0.81 & -3.920 & -3.24 \\
\hline & 176 & -1.03 & 262 & 2.38 & 2.706 & 2.36 & 6.642 & 2.85 \\
\hline & & 1.72 & $-\varepsilon$ & -3.23 & 3.408 & 2.89 & 0.133 & 0.08 \\
\hline & & 1.31 & -40 & -1.53 & -0.730 & -0.23 & -3.436 & -0.88 \\
\hline & & 0.00 & & -2.92 & 1.021 & 0.35 & -3.815 & -1.71 \\
\hline & 064 & -1.50 & & 0.80 & 4.186 & 1.09 & -2.765 & -1.25 \\
\hline & & 1.36 & & -1.57 & & 1.49 & 4.426 & 0.89 \\
\hline & & 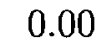 & -2. & -0.16 & -3.715 & -0.62 & 0.915 & 0.07 \\
\hline & & U. & & 0.30 & 6.800 & 0.29 & 18.470 & -0.36 \\
\hline \multirow[t]{2}{*}{ eye problem } & & & -8.897 & -2.61 & 3.414 & 1.76 & -5.484 & -1.81 \\
\hline & \multicolumn{8}{|c|}{ Non-Infants } \\
\hline & 4.160 & & -7 & -9.38 & 2.842 & 5.75 & -4.444 & -6.12 \\
\hline & 4.630 & 2. & 5 & -2.76 & 29 & 42 & -4.857 & -2.96 \\
\hline & 67 & 2.20 & -6.620 & -3.27 & 4.846 & 3.45 & 7.958 & 2.96 \\
\hline & 2.446 & 2.21 & -6 & -4.13 & 2.324 & 2.74 & 0.264 & 0.24 \\
\hline & 5.789 & 4.84 & -11.554 & -6.99 & 1.835 & 2.03 & -2.512 & -1.68 \\
\hline & & 0.92 & & -2.11 & & & -4.066 & -1.28 \\
\hline & $?$ & 2 & & -3 & 5.677 & 5 & -2.156 & -1.48 \\
\hline & & 0.82 & -10 & -1.03 & 4.349 & 1.09 & 3.892 & 0.72 \\
\hline Pelvic Infl. Dis. & 6.298 & 3.49 & & -2.24 & 1.441 & 0.68 & -0.999 & -0.42 \\
\hline & & 3.58 & -10 . & -4.01 & 2.465 & 1.56 & -3.939 & -1.78 \\
\hline & & 1. & $-7 .($ & -2.04 & 7.839 & 3.22 & -9.541 & -1.60 \\
\hline ey & -0.409 & -0.32 & 0.094 & 0.05 & 0.950 & 0.73 & 7.175 & 2.84 \\
\hline
\end{tabular}

log likelihood $=-1352.47$

Mixed conditional/multinomial logit regression. Dependent variable is choice of institution (government, Roman Catholic and Lutheran). Multinomial coefficients for gov. normalized to zero. Positive (negative) coefficient on illness condition/resource interaction implies the presence of the resource makes patient more (less) likely to visit when they suffer from that illness condition. 
are evaluating their illness condition when they choose a provider and that they have an image of the resources available that is significantly correlated with objective measures of the resources that actually are available.

\subsubsection{Potential Data Issues}

Expected Costs The variables intended to capture information about expected costs are highly significant as well. Clearly there are differences between institutions in expected costs that varies by illness condition though not significantly by age or gender. Note that this collection of variables (entering as multinomial coefficients, holding the vector of coefficients for the government equal to zero) could be capturing considerably more information than just expected differences in price. Assume that all Roman Catholic facilities are thought to be better at curing pneumonia than facilities of other institutions and that the reasons for this reputation are not correlated with our measures of quality (CONS SCORE, PRESCRIPTION, MALARIA INJ or NUM DRUGS). Note that this feature is attached to institutions - all Roman Catholic - rather than facilities. Then the data will show more visits to Roman Catholic facilities for pneumonia than would otherwise be predicted and attribute this - incorrectly

- to Roman Catholic facilities charging lower fees for pneumonia than facilities of other institutions.

Our measures of expected costs are likely to be picking up effects that are not due to differences in expected costs. The goal of this variable (and collection of coefficients) is not an accurate picture of expected costs but a control for expected costs that allows us to make inferences about the patterns displayed in the illness condition / resource interaction terms. When the willingness to travel to visit clinics for patients who have pneumonia is correlated with the presence of an above average consultation quality (CONS SCORE) then this should be picked up in our interaction terms. 
Endogenous Facility Location, and Specialization All of the clinics we examine in this paper are basically similar in terms of training and facilities. Some have a broader supply of medicines and some have more doctors than others, but we are not examining hospitals in this data. Every illness in this data set could potentially have been given a preliminary examination at all facilities. However, it is possible that certain facilities specialize in particular illnesses. Specialization is a type of skill variable which would not be captured in our measures of technical quality. If the facility gets a reputation for specialization then patients will choose to visit them more often than our behavioral model would have predicted. Can this introduce bias in our data? If the specializations are randomly distributed between facilities then this should not introduce any bias. The fact that we use data on 17 different facilities helps reduce the chance that we have found spurious correlations.

Of greater concern is the fact that a given institution might specialize in a particular illness or that a given institution chooses to place its facilities in places where the prevalence of a particular illness is different from the average. We do not have significant variance in institutions. However, any bias introduced in this manner (which we cannot empirically dismiss, but which seems unlikely) will be captured in the multinomial coefficients which are supposed to control for differences in costs. This bias should not be transferred to the illness condition / resource interaction terms.

Intra--Institutional Changes in Expected Costs Intra-institutional variation in expected costs is a particularly dangerous problem. If this variation is correlated with any of our quality scores it will introduce bias. A likely scenario is the following. A particular facility tends to over-use injections when compared to other facilities within its institution (say, the Roman Catholic health system). As a result the average cost of a consultation is much higher for those illnesses where injections are more liberally used. This increase in expected cost (which is known to patients) reduces the number of visits for that particular illness. When the data shows a less than predicted number of visits for a particular illness 
condition correlated with above average use of injections, it will attribute this to patients avoiding over-use of injections for that particular illnesses.

Our data undoubtably contains this type of bias, particularly in the injection category (MALARIA INJ). It is not clear that such a bias would exist for CONS SCORE, or PRESCRIPTION but it certainly could for NUM DRUGS. Thus we have to be careful when we draw conclusions for these variables. We cannot say for sure that patients avoid over-use of injections for reasons that have nothing to do with the extra costs associated with injections. It is possible that patients avoid facilities that over-use injections or prescribe too many drugs partially, mainly or entirely because of the extra cost associated with these features.

However, the standard assumption in policy circles has been that patients seek facilities that over-use injections despite the extra costs associated. This proposition can clearly be dismissed by our data.

\subsection{Do these patterns make medical sense?}

We have discovered strong patterns in the data, is there a medical logic behind these patterns? In order address this question we rerun the analysis examining the interactions as differences from the average condition. Thus we include 8 new variables in this second regression, CONS SCORE interacted with infants and non-infants and MALARIA INJ, PRESCRIPTION and NUM DRUGS similarly interacted. The results are shown in Table 10 and Table 11 with Table 11 summarized as Table 12 .

Overall, patients are attracted to the good qualities of health facilities and are repulsed by the negative qualities of health facilities. There are differences between the overall patterns for infants and non-infants but we cannot conclude from these types of variables if the value of health is larger for infants than for non-infants. All of the quality scores have been normalized so that they can be compared to each other. For infants the order of importance is MALARIA INJ, TEST SCORE, PRESCRIPTION, CONS SCORE, NUM DRUGS, ATTENTIVENESS, with no significant difference between PRESCRIPTION and CONS SCORE. For adults the order is 
Table 9: Summary of Illness Condition Resource Interactions from Table 8 Infant

\begin{tabular}{|c|c|c|c|c|}
\hline & CONS SCORE & MALARIA INJ & PRESCRIPTION & NUM DRUGS \\
\hline malaria & ++ & -- & ++ & $\overline{c-}$ \\
\hline upper rti & & & & \\
\hline pneumonia & & ++ & ++ & ++ \\
\hline cough & + & - & ++ & \\
\hline injury & & - - & & \\
\hline diarrhea & & - - & & - \\
\hline dysentery & & & ++ & \\
\hline $\begin{array}{l}\text { scabies } \\
\text { sores / abscess }\end{array}$ & & & & \\
\hline worms & & & & - \\
\hline eye problem & & - & + & - \\
\hline & & Non-Infant & & \\
\hline
\end{tabular}

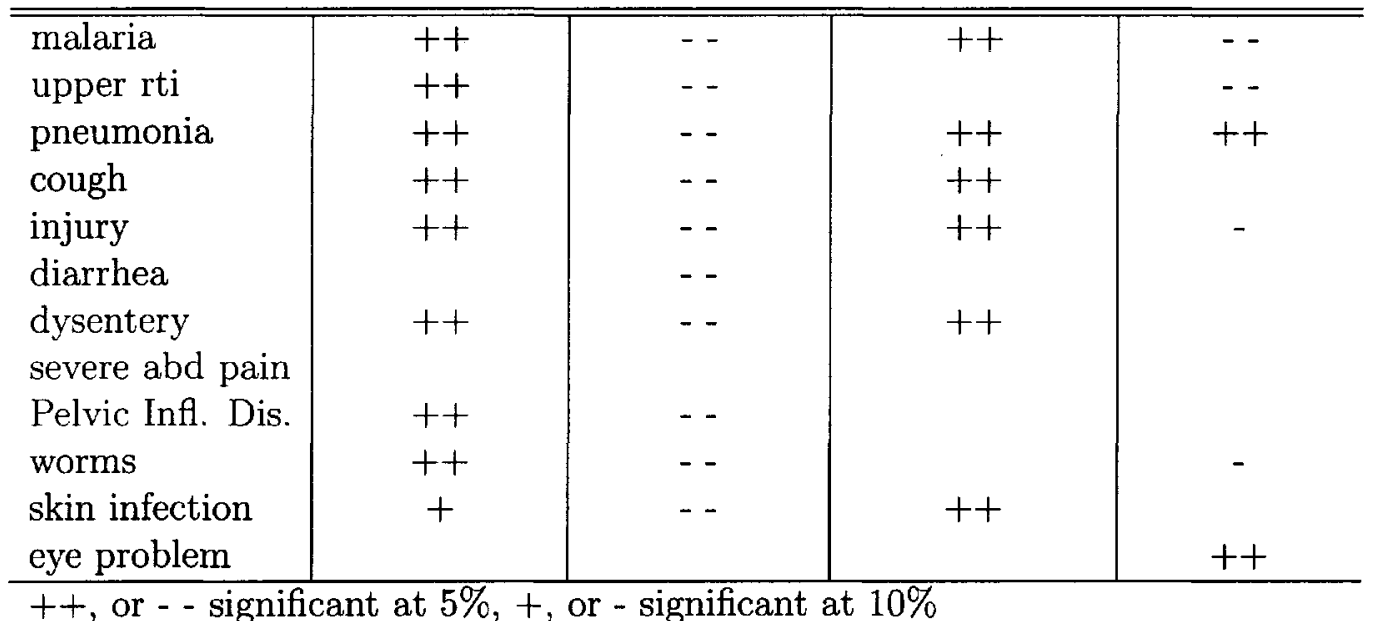

MALARIA INJ, TEST SCORE, NUM DRUGS, CONS SCORE, PRESCRIPTION and ATTENTIVENESS with no significant difference between PRESCRIPTION and ATTENTIVENESS.

The larger average patterns make absolute sense; patients pursue what is good for health care and avoid (or are unwilling to pay the extra costs associated with) what is bad, or unnecessary for health care. Table 12 is a summary table of the coefficients in Table 11 similar to Table 9 except that each illness condition / resource interaction is examined as a deviation from the average. We turn now to these deviations from the averages to see if they make any sense from a medical perspective. 
Table 10: Predicting Visits with Illness Condition / Resource interactions: deviations from average (cont. as Table 11)

\begin{tabular}{|c|c|c|c|c|c|c|c|c|}
\hline & \multicolumn{2}{|c|}{ R. Catholic } & \multicolumn{2}{|c|}{ Lutheran } & & & & \multirow[b]{3}{*}{ z-test } \\
\hline Multinomial Coe & Coef. & z-test & Coef. & z-test & \multirow{2}{*}{\multicolumn{2}{|c|}{ Conditional Coef. }} & \multirow[b]{2}{*}{ Coef. } & \\
\hline constant & 4.507 & 3.07 & 15.871 & 8.15 & & & & \\
\hline age (years) & -0.029 & -1.46 & -0.018 & -0.74 & TRAVE & DIST & -0.54 & -23.93 \\
\hline infant $(0-5)$ & -1.861 & -0.63 & 3.531 & 1.05 & TES & CORE & 5.14 & 17.27 \\
\hline child (5-10) & 0.579 & 0.70 & 0.191 & 0.20 & ATTH & IVENESS & 2.65 & 4.91 \\
\hline youth $(10-16)$ & -0.994 & -1.34 & -1.336 & -1.53 & & & & \\
\hline \multirow[t]{2}{*}{ female } & -0.203 & -0.55 & -0.554 & -1.43 & & & & \\
\hline & \multicolumn{2}{|c|}{ R. Catholic } & \multicolumn{2}{|c|}{ Lutheran } & \multicolumn{2}{|c|}{ R. Catholic } & \multicolumn{2}{|c|}{ Lutheran } \\
\hline variable & Coef. & z-test & Coef. & z-test & Coef. & z-test & Coef. & z-test \\
\hline malaria & 2.122 & 0.78 & 1.941 & $\overline{0.64}$ & 1.887 & 1.20 & $\overline{5.392}$ & $\overline{2.66}$ \\
\hline upper rti & -1.029 & -0.32 & -7.540 & -2.04 & -3.656 & -1.09 & -2.389 & -0.70 \\
\hline pneumonia & -14.761 & -3.35 & -26.091 & -4.63 & -3.585 & -0.91 & -11.404 & -1.77 \\
\hline cough & 7.030 & 1.56 & 6.161 & 1.10 & 3.151 & 1.02 & 2.936 & 0.79 \\
\hline injury & 37.630 & 1.20 & 47.396 & 0.89 & 6.321 & 2.69 & 0.307 & 0.09 \\
\hline diarrhea & 23.655 & 2.72 & 23.300 & 1.37 & -3.337 & -0.82 & 4.984 & 0.80 \\
\hline dysentery & 0.741 & 0.11 & -15.501 & -1.62 & 4.255 & 1.74 & 7.562 & 2.56 \\
\hline worms & -28.270 & -0.19 & 2.308 & 0.04 & 2.898 & 0.66 & 4.357 & 0.33 \\
\hline eye problem & 7.748 & 1.43 & 8.395 & 1.11 & -14.934 & -3.20 & -32.621 & -4.05 \\
\hline scabies & -2.264 & -0.30 & -13.099 & -1.12 & & & & \\
\hline sores/abscess & -2.804 & -0.11 & -19.214 & -0.48 & & & & \\
\hline severe abd pain & & & & & 7.238 & 0.49 & -7.272 & -0.36 \\
\hline Pelvic Infl. Dis. & & & & & -6.202 & -1.70 & -4.727 & -1.05 \\
\hline skin inf. & & & & & 5.257 & 1.66 & 7.189 & 1.45 \\
\hline
\end{tabular}

\subsubsection{Infants}

The process of reaching a diagnoses with symptoms in the illness condition categories of URTI, pneumonia and dysentery in infants might reasonably be seen as straightforward. In other words, caretakers of infants who suffer from these conditions have already decided that certain medication is indicated and they seek facilities for their reputation for providing these medications. For dysentery and pneumonia the loss of time resulting from a decision to bypass the closest facility is not worth the gains from increased consultation quality. On the other hand, for each of these two conditions patients avoid facilities that give too many injections less than they otherwise would. This does not mean that the caregivers expect 
Table 11: Predicting Visits with Illness Condition / Resource interactions: deviations from average (cont. from Table 10)

\begin{tabular}{|c|c|c|c|c|c|c|c|c|}
\hline & \multicolumn{2}{|c|}{ CONS SCORE } & \multicolumn{2}{|c|}{ MALARIA INJ } & \multicolumn{2}{|c|}{ PRESCRIPTION } & \multicolumn{2}{|c|}{ NUM DRUGS } \\
\hline & Coef. & z-test & Coef. & $\mathrm{z}$-test & Coef. & z-test & Coef. & $z$-test \\
\hline & \multicolumn{8}{|c|}{ Infants } \\
\hline average & 4.55 & $\overline{3.53}$ & -6.36 & -3.86 & 4.91 & 4.41 & -3.59 & -2.16 \\
\hline malaria & -1.22 & -0.95 & -0.69 & -0.42 & -1.08 & -0.96 & -1.05 & -0.59 \\
\hline upper rti & -5.68 & -3.54 & 5.80 & 2.99 & -3.14 & -2.12 & -1.03 & -0.51 \\
\hline pneumonia & -5.17 & -3.55 & 9.08 & 4.47 & -1.43 & -0.93 & 9.14 & 3.78 \\
\hline cough & -1.11 & -0.51 & -3.62 & -1.20 & -0.99 & -0.64 & 3.40 & 1.37 \\
\hline injury & 5.80 & 0.64 & -37.98 & -1.16 & -4.95 & -1.27 & -0.95 & -0.18 \\
\hline diarrhea & -2.40 & -0.91 & -13.92 & -1.97 & -2.49 & -0.80 & -0.48 & -0.15 \\
\hline dysentery & -6.52 & -3.34 & 7.68 & 2.14 & 0.91 & 0.20 & 0.67 & 0.22 \\
\hline scabies & 2.86 & 0.50 & -3.67 & -0.62 & 0.44 & 0.12 & 7.91 & 1.33 \\
\hline sores/abscess & -2.16 & -0.15 & -0.10 & -0.01 & -7.76 & -0.98 & 2.06 & 0.12 \\
\hline worms & 1.54 & 0.02 & 11.69 & 0.32 & 3.43 & 0.08 & -18.26 & -0.20 \\
\hline \multirow[t]{2}{*}{ eye problem } & -1.42 & -0.56 & -2.51 & -0.68 & 0.24 & 0.11 & -3.95 & -1.04 \\
\hline & \multicolumn{8}{|c|}{ Non-Infants } \\
\hline average & 3.28 & 4.75 & -6.60 & -6.60 & 2.76 & 4.48 & -4.10 & -4.83 \\
\hline malaria & 1.24 & 1.57 & -2.24 & -1.91 & 0.73 & 1.03 & -1.30 & -1.21 \\
\hline upper rti & 2.35 & 1.00 & -2.32 & -0.75 & 0.27 & 0.17 & -1.23 & -0.62 \\
\hline pneumonia & 2.55 & 1.17 & -4.08 & -1.55 & 2.72 & 1.68 & 10.05 & 3.09 \\
\hline cough & -0.31 & -0.22 & -1.79 & -0.90 & 0.00 & 0.00 & 3.94 & 2.56 \\
\hline injury & 2.68 & 1.97 & -6.07 & -3.14 & -0.44 & -0.39 & 1.06 & 0.56 \\
\hline diarrhea & -1.78 & -0.95 & 1.27 & 0.48 & 0.27 & 0.16 & -1.87 & -0.54 \\
\hline dysentery & -1.16 & -0.97 & 0.71 & 0.43 & 3.54 & 3.10 & 1.06 & 0.65 \\
\hline severe abd pain & 6.82 & 0.60 & -9.14 & -0.66 & 2.49 & 0.47 & 5.28 & 0.80 \\
\hline Pelvic Infl. Dis. & 3.89 & 2.03 & 0.52 & 0.21 & -1.70 & -0.72 & 2.12 & 0.83 \\
\hline worms & 3.02 & 1.75 & -5.56 & -2.04 & 0.11 & 0.06 & -0.49 & -0.18 \\
\hline skin inf. & 1.96 & 0.62 & -1.18 & -0.34 & 5.75 & 2.32 & -6.72 & -0.97 \\
\hline eye problem & -3.99 & -2.72 & 6.49 & 2.85 & -1.52 & -1.02 & 12.86 & 4.50 \\
\hline
\end{tabular}

$\log$ likelihood $=-1274.54$

Mixed conditional/multinomial logit regression. Dependent variable is choice of institution (government, Roman Catholic and Lutheran). Multinomial coefficients for gov. normalized to zero. Positive (negative) coefficient on illness condition/resource interaction implies the presence of the resource makes patient more (less) likely to visit when they suffer from that illness condition than if they suffered from the average condition. 
Table 12: Summary of Illness/Resource Seeking from Table 11: Deviation from Average

\begin{tabular}{|c|c|c|c|c|}
\hline & CONS SCORE & MALARIA INJ & PRESCRIPTION & NUM DRUGS \\
\hline infant average & ++ & -- & ++ & -- \\
\hline $\begin{array}{l}\text { malaria } \\
\text { upper rti } \\
\text { pneumonia } \\
\text { cough } \\
\text { injury } \\
\text { diarrhea } \\
\text { dysentery } \\
\text { scabies } \\
\text { sores / abscess } \\
\text { worms } \\
\text { eye problem } \\
\text { ear problem } \\
\end{array}$ & $\begin{array}{c}-- \\
-- \\
--\end{array}$ & $\begin{array}{l}++ \\
++ \\
\\
-- \\
++\end{array}$ & -- & ++ \\
\hline non-infant average & ++ & $\overline{-1-}$ & ++ & $\overline{-1-}$ \\
\hline $\begin{array}{l}\text { malaria } \\
\text { upper rti } \\
\text { pneumonia } \\
\text { cough } \\
\text { injury } \\
\text { diarrhea } \\
\text { dysentery } \\
\text { severe abd pain } \\
\text { Pelvic Infl. Dis. } \\
\text { worms } \\
\text { skin infection } \\
\text { eye problem }\end{array}$ & $\begin{array}{c}++ \\
\\
++ \\
+ \\
--\end{array}$ & $\begin{array}{c}\cdots \\
\\
\ldots \\
++\end{array}$ & $\begin{array}{c}+ \\
++ \\
++ \\
++\end{array}$ & $\begin{array}{l}++ \\
++\end{array}$ \\
\hline
\end{tabular}

++ , or - - significant at $5 \%,+$, or - significant at $10 \%$ 
injections (though they should for pneumonia) but rather that they prefer facilities that over-use strong medication. In the case of pneumonia they prefer centers that prescribe too many drugs as well. Not only do caregivers seek over-prescription for pneumonia more that the average patient, but they seek it absolutely (see Table 9). The proper cure for pneumonia does not indicate an over-use of drugs and therefore, if patients can be sure of getting the correct drug they should not seek (or even tolerate) facilities that use too many medications. However they may do so out of fear or insecurity that only one drug will do the job when infants have pneumonia. In other words, though they appear to be engaging in an unnecessary activity, pneumonia can be severe and perhaps caregivers are willing to incur additional expense.

For URTI, travel time does not appear to be a concern; Table 6 shows that for URTI in infants, distance gradients are significantly flatter than average. In addition, caregivers are less concerned that the prescription be properly filled than for the average condition. URTI is the kind of condition for which patients seek relief from symptoms more that a cure, so this makes some sense.

Why the caregivers of infants who suffer from diarrhea are less likely than average to seek over-injections is not directly obvious. They would not seek injections, but why they would have a differential aversion to injections we cannot say.

\subsubsection{Non-Infants}

It makes complete sense that patients with PID seek high quality diagnostic care, although we would have expected them to do so for severe abdominal pain as well. Injuries, could, in many cases require the same kinds of skill or effort that are seen in diagnosis, though it is not true to say that diagnosis is complicated in the case of an injury since the source of the injury is usually clear. That patients seek diagnostic quality for the diagnosis of worms does not have an obvious interpretation to us. Worms should be easy to diagnose. They do not require injections or strong medication so it does make sense that patients are unwilling to 
pay extra to seek centers that tend to over use injections. Patients with eye problems are seeking medicine and a willingness to use those medications.

The fact that patients seek diagnostic quality in the case of pneumonia, dysentery and skin infections makes sense since these conditions respond well to the correct medication. In addition, patients might tolerate facilities that use too many drugs in the case of pneumonia and cough since relatively inexpensive medication is useful for alleviating symptoms.

That patients avoid overuse of injections in the case of injury, worms and eye problems make sense because (in large part) these conditions do not require medication delivered by injection. When the injury is such that it would require an injection, this would be the case no matter where the patient visits.

It cannot be said that every case in this table represents exactly the behavior that the very best doctor would recommend to a patient. However, broadly speaking, the patterns do represent well-informed behavior, rather than either a random collection of significances or an entirely ignorant matching of resources and illnesses.

\section{Conclusion}

After controlling for the factors that would be associated with expected costs our data shows that patients appear to know about and use information about levels of technical quality present at the various health facilities between which they choose. The simple patterns shown in the data do not fully support a medically inspired rational view of health facility use, but they do appear to be based on medically sound judgement. These findings are very important because they display sophistication on the part of patients that has not been previously documented. 


\subsection{Learning about "Unobservable" Features of Facilities}

Although there is strong evidence that patients know about unobservable features of health facilities, this paper cannot say how patients learn about such features. We suggest a few possible mechanisms through which learning could be taking place.

Institutional Reputation Potential patients may have opinions about the services associated with institutions as a whole. Under such a regime Roman Catholic, Lutheran and government services are seen as different, but all clinics within an institution are similar. There is some institutional reputation since institutions across Africa take great care to associate new facilities with existing facilities (calling the new facility an 'annex' of an old one even if it is geographically isolated from the existing one, for example (Leonard, forthcoming, pp. 23-24)). Our data clearly dismisses this as the only method of learning, thought it might be an important component of the process.

Institutional and Clinic Organization Potential patients may form some type of understanding of the incentives at work in any given clinic. Most of the clinics operated by one institution face the same incentives, but there are differences, and patients could be aware of these. Although this can, in theory, be tested, the current data does not have any within institution variation in incentives and cannot be used to test this theory.

Physician or Clinic Reputation Observing the outcomes of many consultations over a long period of time should produce a relatively accurate picture of all aspects of quality at any given clinic. Thus, over time, patients would develop an image of the quality available at every clinic. In this case patients would not need to have any idea which resources were useful for which cases. Instead they would observe that a particular clinic was better than another for one illness but not for another. The patterns we find would be the result of the "true" importance of resources in illnesses. This is a very compelling view (since it requires patients to be able to observe lots of outcomes, but not to have strong medical information), 
but we do not have a theory of how long it would take for patients to update information when the menu of resources changed.

Correlates of Unobservable Quality Patients may have an accurate view of quality because they are able to observe some feature of a center that is correlated with quality. We have been unable to identify such a feature in our research but that does not mean that it does not exist - we have shown, for example, that politeness is not such a correlate. This would work well to explain one aspect of quality, but it does not map well onto a world in which patients understand multiple aspects of quality as each aspect would need a separate identifiable correlate.

Quality is Observable It is possible that patients can evaluate quality and there is no asymmetric information in health care. If this were true, however, we would expect to see patients negotiating with practitioners directly over the provision of quality services. There is little to stop this type of negotiation and yet it is not observed. We cannot dismiss this proposition based on the data used in this paper since our model does not allow for this type of behavior, but we know from out previous experience that this is not the case.

The sophistication of patients in their health seeking behavior does have some immediate implications even without understanding the mechanism by which the information is obtained. It is common wisdom among policy makers in Tanzania that patients prefer injections and visit facilities that are more willing to provide them. This is a concern because the health system cannot afford new needles for each injection and sterilization techniques are not always perfect, allowing needles to serve as a vector of contamination. Injections are assumed to be popular because we observe high demand for facilities that over-use injections. However, there is significant correlation between over-use of injections and other measures of technical quality. Facilities that are decentralized and rely on revenue to remain open find injections to be a lucrative source of income; patients are asked to pay more for injections 
than they would for the same medication delivered orally. We do not observe patients arguing with medical staff and asking not to have injections. However, when we can observe technical quality independently of the proclivity to use injections we see that patients are not attracted to facilities that over-use injections. We cannot differentiate between patients who know that injections can be dangerous and patients who are not willing to pay the extra cost associated with injections, but we can see that they are not attracted to the combination of injections and extra costs. This particular result is interesting because it is contrary to prevailing wisdom but the results on the other three measures of quality are as important to policy.

Further conclusions about particular aspects of policy are dangerous. We have not attempted to model supply. We do not know the costs of supplying various measures of quality so we cannot investigate the optimality of decisions to change the quality levels that are available. We have assumed supply decisions are exogenous to the patient's decision. However, at the very least, quality is rewarded in this context. We cannot speculate on what a private practitioner would choose to provide, and indeed previous work suggests that regulation of health services is likely to be essential to quality. However, if the quality delivered by regulation were punished it would have terrible implications for the future of decentralization efforts in rural health care.

As a general policy conclusion, however, it is important to realize that patients will have a double benefit from improvements in quality. First, all visitors to a center which increases its quality will benefit and secondly, new patients will be attracted to this center. Those which had previously incurred significant travel cost to avoid the center will benefit from increased quality and decreased avoidance costs. Travel costs are a transaction cost in the context of health seeking behavior. They reflect a willingness to purchase health care that is transferred to other elements of the economy (bus drivers, for example) and not retained in the health sector. When patients bypass facilities that are equipped to handle their cases (but do not deliver the services due to asymmetric information) this is a significant loss of 
value. (For discussion see Leonard, ed (2000, pp. xxxii-xxxiii) and Haile Mariam (2000)). Increases in quality that lead to less bypassing are a unilateral reduction in waste. 


\section{References}

Online documents are avaiable at www.columbia.edu $/{ }^{\sim} \mathrm{kl} 206 / \mathrm{research.html}$

Abel-Smith, B. and P. Rawal, "Can the Poor Afford 'Free' Health Services? A Case Study of Tanzania," Health Policy and Planning, 1992, 7, 329-41.

Acton, Jan Paul, "Nonmonetary Factors in the Demand for Medical Services: Some Empirical Evidence," Journal of Political Economy, 1975, 83 (3), 565-614.

Akin, J. S. and P. Hutchinson, "Health-care facility choice and the phenomenon of bypassing," Health Policy and Planning, 1999, 14 (2), 135-51.

_ , C. C. Griffin, D. K. Guilkey, and B. M. Popkin, The Demand for Primary Health Services in the Third World, Totowa, New Jersey: Roman and Allanheld, 1985.

$\ldots, \ldots, \ldots$, and $\ldots$, "The demand for primary health care services in the Bicol region of the Philippines," Economic Development and Cultural Change, 1986, 34 (4), 755-782.

Arrow, K. J., "Uncertainty and the Welfare Economics of Medical Care," American Economic Review, 1963, 53 (5), 941-973.

_ , "Agency and the Market," in K.J. Arrow and M.D. Intriligator, eds., Handbook of Mathematical Economics, Vol. 3, Elsevier Science Publishers, 1986, pp. 1183-1195.

Bichmann, W. et al., "District Health Systems: Users' Preferences for Services in Benin," Health Policy and Planning, 1991, 6, 361-70.

Dor, Avi, Paul Gertler, and Jacques van der Gaag, "Non-Price Rationing and the Choice of Medical Care Providers in Rural Cote D'Ivoire," Journal of Health Economics, December 1987, 6 (4), 291-305.

Dranove, D. and W. D. White, "Agency and the Organization of Health Care Delivery," Inquiry, 1987, 24, 405-415.

Gaynor, M., "Issues in the Industrial Organization of the Market for Physician Services," Journal of Economic Management and Strategy, 1994, pp. 211-255.

Gertler, P. and J. Van der Gaag, The Willingness to Pay for Medical Care: Evidence from two developing countries, Baltimore, Maryland: Johns Hopkins University Press, 1990. Published for The World Bank.

Haile Mariam, Damen, "Traditional Insurance Mechanisms and the Choice of Health Care Providers in Ethiopia." In Leonard, ed (2000) chapter 2.

Kabakian-Khasholian, T., O. Campbell, M. Shediac-Rizkallaha, and F. Ghorayebc, "Women's experiences of maternity care: satisfaction or passivity?," Social Science and Medicine, 2000, 51 (1), 103-113.

Kloos, Helmut, "Utilization of selected hospitals, health centers and health stations in Central, Southern and Western Ethiopia," Social Science and Medicine, 1990, 31 (2), 101-114.

Leonard, David K., ed., Africa's Changing Markets for Human and Animal Health Services, London: Macmillan, 2000. 
Leonard, Kenneth L., "African Traditional Healers and Outcome-Contingent Contracts in Health Care," mimeo (available on-line), Columbia University 2000.

_ , "Agency in Health Care: An Empirical Investigation in Rural Cameroun," mimeo (available on-line), Columbia University 2000.

_ , "Incentives and Rural Health Care Delivery." In Leonard, ed (2000) chapter 4.

_, "When States and Markets Fail: Asymmetric Information and the Role of NGOs in African Health Care," International Review of Law and Economics, forthcoming. (available on-line).

Litvack, J. I. and C. Bodart, "User fees plus quality equals improved access to health care: results of a field experiment in Cameroun," Social Science and Medicine, 1993, 37 (3), 369-383.

Maddala, G.S., Limited-Dependent and Qualitative Variables in Econometrics, Cambridge, UK: Cambridge University Press, 1983.

McGuire, T., "Physician Agency," in A.J. Culyer and J.P. Newhouse, eds., Handbook of Health Economics, Elsevier Science Publishers, 2000, pp. 461-536.

Mliga, Gilbert R., "Decentralization and the Quality of Health Care." In Leonard, ed (2000) chapter 8.

Mooney, Gavin and Mandy Ryan, "Agency in Health Care: getting beyond first principles," Journal of Health Economics, 1993, 12, 125-135.

Mwabu, Germano M., "Health Care Decisions at the Household Level: Results of a Rural Health Survey in Kenya," Social Science and Medicine, 1986, 22, 315-19.

Ndeso-Atanga, Sylvester, "Health Care Quality and the Choice of Care Providers in Rural Cameroon." In Leonard, ed (2000) chapter 5.

Nougtara, A. et al., "Assessment of MCH Services Offered by Professional and Community Health Workers in the District of Solenzo, Burkina Faso. 1 Utilization of MCH Services," Journal of Tropical Pediatrics, 1989, 35, 2-9.

Omorodion, F.I., "The Socio-Cultural Context of Health Behavior Among Esan Communities, Edo State, Nigeria," Health Transition Review, 1993, 3, 125-36.

Parsons, T., The Social System, Glencoe, Ill: The Free Press of Glencoe, 1951.

Sauerborn, R. et al., "Low Utilization of Community Health Workers: Results from a Household Interview Survey in Burkina Faso," Social Science and Medicine, 1989, 29, 1163-74.

Stock, Robert, "Distance and the Utilization of Health Facilities in Rural Nigeria," Social Science and Medicine, 1983, 17 (9), 563-570.

Waddington, C.J. and K.A. Enyimayew, "A price to pay: The impact of user charges in Ashanti-Akim district, Ghana," International Journal of Health Planning and Management, 1989, 4, 17-47.

Yoder, R.A., "Are People Willing and Able to Pay for Health Services?," Social Science and Medicine, 1989, 29, 35-42. 


\section{A Illness Coding}

\begin{tabular}{|c|c|}
\hline Illness Condition & Other illness or conditions \\
\hline malaria & fever and headache (no other $\mathrm{s}$ \\
\hline er respiratory infection & $\begin{array}{l}\text { acute respiratory infection, tonsilitis, sore throat, } \\
\text { corryza }\end{array}$ \\
\hline pneur & $\begin{array}{l}\text { bronchial pneumonia, respiratory tract infection, } \\
\text { lung infection }\end{array}$ \\
\hline cough & itis, common cold \\
\hline & trauma \\
\hline & gast \\
\hline dys & ameobiasis, bloody diarrhea, giardiasis \\
\hline blems & itis, \\
\hline $\mathrm{w}$ & 1, ascaries \\
\hline se & , colic \\
\hline pel & A se \\
\hline skin & $\begin{array}{l}\text { pellagra, dermatitis, fungal infection, scalp fun- } \\
\text { gus, impetigo }\end{array}$ \\
\hline sexually transmitted disease & $\begin{array}{l}\text { genital sores, gonnohrea, syphillis, trichomonosis, } \\
\text { gonnococcal infection }\end{array}$ \\
\hline chest & hypertension, heart palpitation, cardiomyopathy \\
\hline & $\operatorname{lin}$ \\
\hline
\end{tabular}




\section{0-01 Discussion Paper Series}

Department of Economics

Columbia University

1022 International Affairs Bldg.

420 West 118th Street

New York, N.Y., 10027

The following papers are published in the 1999-00 Columbia University Discussion Paper series. The series runs from September $1^{\text {st }}$ to August $31^{\text {st }}$ (formerly from November $1^{\text {st }}$ to October $31^{\text {st }}$ ).

All papers from 9798 to 9900 will be accessible on-line at the following website:

http://www.SSRN.Com/

Some papers from 1995 to 1997 are available and may be downloaded from the following website:

http://www.columbia.edu/dlc/wp/econ/index.html.

\section{Copy Requests}

\section{Current Papers (backdated to 9798 series):}

Please go to the SSRN website (see above) to access discussion papers in full text. Hardcopies are not available if papers may be accessed on-line.

\section{Past Discussion Papers:}

Past discussion papers (1996-97 and prior papers) are available for purchase in U.S. dollars only, at the cost of :

U.S. per paper $\$ 4.00 /$ Per series: $\$ 140.00$

Canada per paper $\$ 5.00 /$ Per series: $\$ 150.00$

Overseas per paper $\$ 7.00 /$ Per series: $\$ 185.00$

To order any of the past series, as above stated, please write to the Discussion Paper Coordinator at the above address, along with a check for the appropriate amount, made payable to: Department of Economics, Columbia University. Please be sure to indicate the discussion paper number or the particular series in your written request. Orders cannot be process without payment, and they cannot be taken over the phone, or by fax or email. 